\title{
Estimación de clases de edad de las plantaciones de la provincia de Corrientes, Argentina, con base en datos satelitales Landsat
}

\author{
Estimation of age classes in plantations of Corrientes province, Argentina, \\ using Landsat satellite data
}

\author{
José Daniel Lencinas ${ }^{a *}$, Diego Mohr-Bell ${ }^{b}$ \\ *Autor de correspondencia: aCentro de Investigación y Extensión Forestal Andino Patagónico CIEFAP, \\ Laboratorio de Percepción Remota y Sistemas de Información Geográfica, casilla 14 (9200), Esquel, Chubut, Argentina, \\ Tel.: +54-2945-453948 int 236, fax: +54-2945-453948 int 505, jdlencinas@ gmx.net \\ bentro de Investigación y Extensión Forestal Andino Patagónico, CIEFAP, Argentina.
}

\begin{abstract}
SUMMARY
In the process of updating the first forest inventory of implanted species in Argentina, stratifying by age class was recommended. The possibility to estimate age classes using Landsat 5 satellite data, was studied due to lack of information regarding this variable for every stand. This study was done over an area of Corrientes Province. The relation between age and digital number values, reflectance values, Tasseled Cap transformation and different vegetation indexes, was analyzed for eucalyptus (Eucalyptus spp.) and pine (Pinus spp.) stands. A significant correlation was found between reflectance values of band 4 and the age of eucalyptus $(\mathrm{r}=-0.58)$ and pine $(\mathrm{r}=-0.79)$ plantations. Equations were constructed in order to predict ages of stands of both genera. These equations estimated age with a mean error of 2.2 years for eucalyptus stands and 3.5 years for pine stands. Baring in mind these results and the stratification by age needed for the mentioned inventory, it is advisable to set two age classes for the age range studied, for both genera.
\end{abstract}

Key words: age estimation, radiometric correction, Landsat 5, Pinus, Eucalyptus.

RESUMEN

En el marco del proceso de actualización del primer inventario forestal de plantaciones en Argentina se recomienda realizar una estratificación por clases de edad. Debido a la falta de información de esta variable para todas las plantaciones, se estudió la posibilidad de realizar una estimación a través de datos satelitales Landsat 5 para una zona de la provincia de Corrientes. Se analizó la relación entre la edad de plantaciones de eucalipto (Eucalyptus spp.) y pino (Pinus spp.) con valores digitales, de reflectancia, componentes de transformación e índices de vegetación. Se determinó una correlación significativa de $-0,58$ y $-0,79$ entre los valores de reflectancia de la banda 4 y la edad para eucalipto y pino, respectivamente. Se construyeron ecuaciones para predecir la edad en ambos géneros. Éstas estimaron la edad con un error medio de 2,2 años en eucalipto y 3,5 años en pino. A partir de los estadísticos determinados y de la posterior validación, y con el fin de implementar una estratificación para el inventario forestal provincial de plantaciones, se propone construir dos clases de edad para el rango de edades estudiado en ambos géneros.

Palabras clave: estimación de edad, corrección radiométrica, Landsat 5, Pinus, Eucalyptus.

\section{INTRODUCCIÓN}

El vertiginoso desarrollo de sensores satelitales modernos permitió ya desde el año 1972 la utilización efectiva y a bajo costo de datos satelitales para la clasificación de tipos de bosques (Schardt 1990, Bodmer 1993), inventarios forestales multifásicos (Poso 1988, Tomppo 1998, Jensen y Köhl 1993, Bauer et al. 1994) y para la estimación cuantitativa de parámetros de rodales (Ahern et al. 1991, Cohen y Spies 1992, Scheer et al. 1997, entre otros). Estas aplicaciones se desarrollaron principalmente en regiones de grandes extensiones, con terrenos inaccesibles o en áreas con baja disponibilidad de información básica y cartográfica. Datos multiespectrales provenientes de la teledetección espacial son utilizados para estimar un amplio espectro de variables biofísicas, tales como volumen (Ärdo 1992, Lencinas 2002) y biomasa de las superficies boscosas, índice de área foliar (Leaf Area Index, LAI) (Eckert et al. 2005), humedad y temperatura.

En relación con la estimación de la edad de forestaciones sobre la base de datos satelitales, ésta depende no sólo de las características de los sensores sino también de los 
parámetros estructurales (altura, área basal, densidad), y factores biofísicos (biomasa, LAI) que van cambiando con la edad del rodal. La edad de las forestaciones no puede ser determinada directamente en base a información de la teledetección espacial, pero puede ser deducida por cambios en la información espectral derivados de los cambios de los parámetros estructurales (Jakubauskas y Price 2000). Si bien Tuominen y Haakana (2005) no investigaron la variable edad, la estimación de atributos estructurales de coníferas (volumen, área basal, altura) con imágenes Landsat ETM+ mostró una mayor eficiencia $(7,0-11,8 \%$ menor RMS) comparada con estimaciones en base a fotografías aéreas de gran altitud (escala 1:60.000). Estos resultados junto a otras investigaciones indican un gran potencial para la extracción de información estructural de bosques en base a datos satelitales (Levesque y King 2003).

Teniendo en cuenta la gran extensión en la cual se localizan las plantaciones de Argentina y el potencial de extracción de información estructural de bosques basándose en datos satelitales, el presente estudio aborda esta temática con el fin de contribuir a optimizar el inventario forestal de plantaciones de la provincia de Corrientes. Este inventario tiene un carácter de fase piloto para la actualización del primer Inventario Nacional de Plantaciones. Según los resultados del Inventario Nacional (SAGPyA 2001), en la provincia de Corrientes se encuentran 217.657 ha de pino (Pinus spp.) y eucalipto (Eucalyptus spp.). Los pinos principalmente elioti (Pinus elliottii Engelm.) y taeda (Pinus taeda L.) representan un 57\% y los eucaliptos, fundamentalmente grandis (Eucalyptus grandis W. Hill ex Maid) un $43 \%$ del total de la superficie.

De acuerdo a los primeros resultados de la digitalización de plantaciones y del análisis de información auxiliar que se está llevando a cabo en esta fase piloto, se estima que actualmente en la provincia de Corrientes se encuentran aproximadamente 300 mil hectáreas de pino y eucalipto ${ }^{1}$. Para tal estimación se digitalizaron según interpretación visual de datos Landsat 5 más de 17 mil plantaciones en macizo mayores a 5 ha.

Para optimizar el inventario terrestre es recomendable estratificar sobre la base de una variable que esté estrechamente relacionada con la variable de interés del muestreo. Para el inventario de Corrientes, el volumen es la variable principal del muestreo y la edad representaría una variable auxiliar que se relaciona estrechamente con el volumen. Por lo tanto se podría optimizar el inventario si se pudiera estratificar la población en función de la edad. Esto significa que si la estratificación se realiza correctamente, se necesitaría menor número de muestras

SAGPyA (Secretaría de Agricultura, Ganadería, Pesca y Alimentación). 2006. Actualización del Inventario Nacional de Plantaciones. Área SIG de la Dirección de Forestaciones. SAGPyA, Inédito. De esta fuente se obtuvieron datos de superficies de plantaciones de pino y eucalipto. para estimar la variable de interés con el mismo error de muestreo (Van Laar y Akça 1997).

Para estratificar por edad es necesario tener una estimación de la edad de todas las plantaciones. Si bien aún se están realizando las gestiones para obtener la edad de la mayor cantidad de las plantaciones digitalizadas posible, a partir de datos suministrados por empresas, inventarios forestales previos, información del Sistema de Promoción de la SAGPyA (Secretaría de Agricultura, Ganadería, Pesca y Alimentos), etc., hasta el momento sólo se cuenta con información de edad de un 59\% de las plantaciones de eucalipto y un $64 \%$ de las plantaciones de pino.

Teniendo en cuenta que para optimizar el inventario se plantea realizar una estratificación por clases de edad ${ }^{2}$, para las plantaciones en las cuales no se logre disponer de tal información, y por los altos costos que requeriría su relevamiento terrestre, se analizan métodos alternativos eficientes para realizar una complementación en la asignación de clases de edad como la estimación de clases de edad en base a valores espectrales de imágenes satelitales.

Por lo tanto, el objetivo de este estudio es evaluar la aptitud de datos satelitales Landsat 5 para la estimación de clases de edad de plantaciones forestales de pino y eucalipto en la provincia de Corrientes.

\section{MÉTODOS}

Área de estudio. El presente estudio se realizó sobre la región noreste de la provincia de Corrientes, que abarca parte de los departamentos de Santo Tomé, General Alvear y San Martín. Se tuvo en cuenta el área abarcada por el path 224 y row 080 de las imágenes Landsat. Se eligió esta área ya que incluye suficiente y adecuada información en cuanto a edades de plantaciones (figura 1).

En el área de estudio definida se encuentran 84.000 ha de pino y 9.900 ha de eucalipto con edades de 0 a 27 y de 0 a 12, respectivamente. En dicha área se encontraron plantaciones de edad conocida para cada año de edad entre el rango de 4 a 27 años para pino y de 4 a 12 años para eucalipto. Si bien existen plantaciones recientes, en el estudio se excluyeron las plantaciones con edades menores a 4 años, debido a su similitud espectral con suelo desnudo o pastizales, que dificultan la detección sobre la base de datos Landsat 5 .

Datos satelitales. Para este trabajo se obtuvieron imágenes Landsat TM5 de invierno-verano con fechas de captura de enero 2005 y julio 2005, a través de un convenio entre CONAE (Comisión Nacional de Asuntos Espaciales) y SAGPyA. Las imágenes Landsat TM5 fueron rectificadas sobre la base de un mosaico de imágenes ASTER generado

\footnotetext{
2 Bava J, H Gonda, JD Lencinas. 2006. Metodología de actualización del inventario nacional de Plantaciones. Segundo informe de avance. Fund. para DFAyEP. Proyecto Forestal de Desarrollo-SAGPYA. Argentina, inédito.
} 


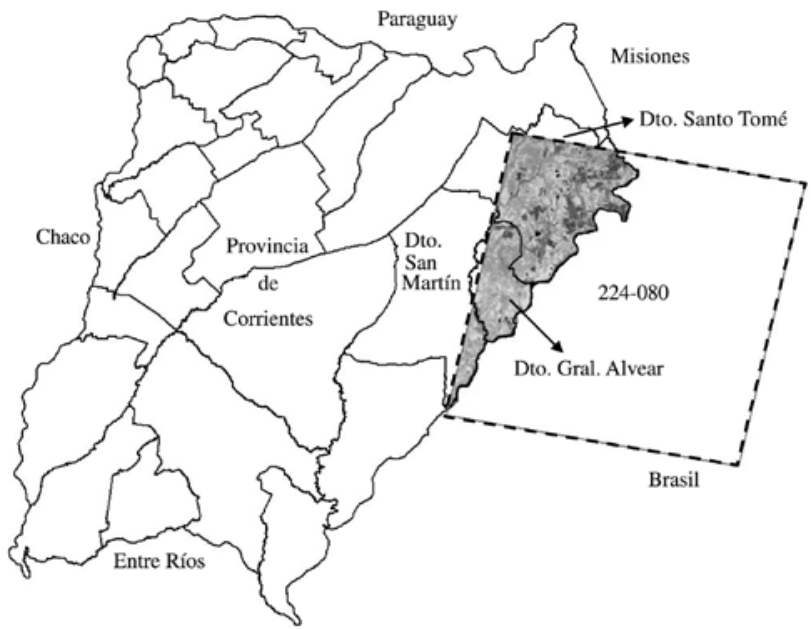

Figura 1. Área de estudio y su ubicación en la provincia de Corrientes. Se muestra también el frame de la imagen Landsat utilizada pasa el estudio (línea segmentada). La imagen de estudio corresponde a un sector del frame 224-080, intersectada por el límite de la Provincia. Las coordenadas geográficas del vértice superior izquierdo de la imagen $224-080$ son: latitud $27^{\circ} 55^{\prime}$ '52" S, longitud 59²5'02" O. (Dto.: Departamento).

Study area and its location in the province of Corrientes. Landsat 224-080 frame (dotted lines) is shown. The studied image is an area of frame 224-080, intersected by the border of the province. The geographic coordinates of the upper left corner of the image are: Lat: $27^{\circ} 55^{\prime}$ 52" Long: 59 25'02”. (Dto.: Department).

en el marco de la actualización del inventario nacional de plantaciones. El sistema de proyección corresponde a Gauss Krüger, con elipsoide y datum WGS84.

Inicialmente, para analizar la conveniencia de utilizar una imagen de verano o de invierno para discriminar edades de plantaciones, se realizó una comparación de las diferencias en valores espectrales de ambas imágenes respecto a plantaciones con diferentes edades. Para esto se seleccionó una muestra independiente de plantaciones para las cuales se calcularon las medias de los valores digitales.

La comparación de valores espectrales de ambas imágenes (verano-invierno) mostró que las diferencias espectrales en edad son más marcadas en una imagen de verano que en una de invierno (figura 2). Teniendo en cuenta la mayor capacidad de diferenciación en la imagen de verano, se decidió utilizar la imagen Landsat 5 con fecha de captura del 17 de enero del 2005 para los análisis. Esto se debe fundamentalmente a que en verano la vegetación se encuentra en su estadio de mayor actividad fotosintética (Hildebrant 1976) y además se minimiza el efecto de las sombras.

Procesamiento de los datos satelitales. Para establecer una relación entre la variable biofísica edad y los valores espectrales de datos satelitales fue necesario realizar una corrección radiométrica. Para ello se reconvirtieron los valores de intensidad (digital number $(\mathrm{DN})$ en escala de
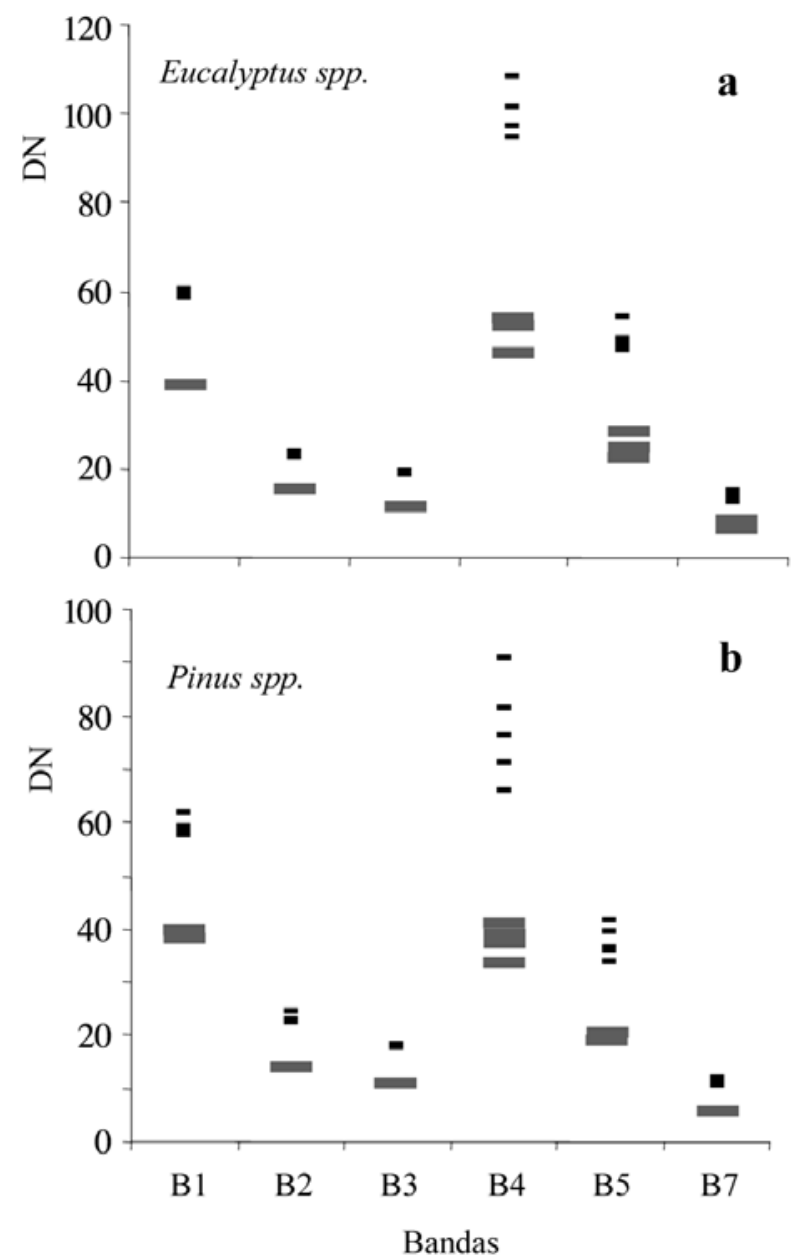

Figura 2. Diferencia en valores digitales (DN) de plantaciones de diferentes edades para cada banda. Se muestrearon cuatro y cinco polígonos, de diferentes edades, abarcando todo el rango de edades de Eucalyptus spp. (a) y Pinus spp. (b). Los polígonos se muestrearon en una imagen de invierno líneas largas (julio 2005) y una de verano líneas cortas (enero 2005).

Difference in digital number (DN) values for plantations of different ages, in each band. Polygons of different ages were sampled trying to cover the entire age range, 4 polygons for Eucalyptus spp. (a) and 5 for Pinus spp. (b). Polygons were sampled on a winter image (July 05) (long grey dashes) and a summer image (January 05) (short black dashes).

grises 8 bit) de cada píxel a valores de reflectancia. El programa ATCOR (Richter 2001) calcula la radiancia $\left[\mathrm{mW} /\left(\mathrm{cm}^{2} \mathrm{sr} \mu \mathrm{m}\right)\right]$, a partir de los valores digitales $(8$ bit) de cada píxel, sobre la base de factores de calibración propios de cada sensor (gain y bias). A partir de los valores de radiancia, el programa calcula los valores de reflectancia (relación entre el flujo reflejado por el píxel y flujo incidente sobre el mismo), descontando el efecto de la radiación refractada por la atmósfera y captada por el sensor (corrección atmosférica), y la radiación reflejada por áreas contiguas (efecto de adyacencia), ya que afectan el valor digital del píxel en consideración. 
Teniendo en cuenta que la topografía de la provincia de Corrientes es relativamente plana con una altitud media en el área de estudio de 150 m s.n.m., se utilizó para la corrección radiométrica el programa ATCOR2 (Richter 2001) de Geomática 9.1.7 de PCI, adecuado para zonas no montañosas. El algoritmo de corrección necesita datos de la captura de la imagen, los cuales se obtuvieron a partir del header file de la misma. Otros datos necesarios fueron los correspondientes a las condiciones atmosféricas propias del área de estudio y se ingresaron como área de definición rural, condiciones de verano a latitud media y visibilidad de $30 \mathrm{~km}$.

Para la corrección radiométrica se utilizaron las bandas visibles e infrarrojas de Landsat TM5 (Bandas 1, 2, 3, 4, 5 y 7). Se especificó también que el programa calculara una máscara de nubes y una de bruma, las cuales son tenidas en cuenta en los cálculos para la corrección. Los factores de calibración (gain y bias) utilizados fueron recomendados por Chandler y Markham (2003) para capturas posteriores al 5 de mayo de 2003. Estos valores derivaron de la curva de calibración radiométrica de la vida útil del sensor, basada en el calibrador interno del mismo. Además se probaron valores de calibración calculados por sobre la imagen utilizada para el estudio.

Finalmente, se decidió utilizar los parámetros calculados debido a que se obtuvieron mejores resultados, los cuales fueron aceptables para las bandas 4, 5 y 7 . Las bandas 1, 2 y 3 no fueron corregidas satisfactoriamente, obteniéndose valores espectrales muy bajos y por lo tanto no se utilizaron para el análisis. En la imagen utilizada se observaron valores radiométricos anormales debido, probablemente, al envejecimiento del sensor TM.

Adicionalmente se calcularon componentes de transformación e índices de vegetación para analizar su relación con la edad de las plantaciones. Para el caso de las transformaciones se generaron tres bandas sintéticas resultantes del tasseled cap (Crist y Kauth 1986), obteniendo bandas correspondientes a los componentes brightness (B), greenness $(\mathrm{G})$ y wetness $(\mathrm{W})$. Tales variables mostraron una satisfactoria correlación con la edad de plantaciones en los estados de Oregon y Washington, Estados Unidos (Cohen y Spies 1992). Con respecto a los índices de vegetación se calcularon el simple ratio vegetation index (SRVI), normalized difference vegetation index (NDVI) e infra red vegetation index (IRVI). El SRVI es la relación entre la reflectancia del infrarrojo cercano (NIR) y el rojo (R). El NDVI se obtiene de la relación de las reflectancias (NIR-R/NIR+R). El IRVI se calcula con la relación (NIR-MIR/NIR+MIR), donde MIR es la reflectancia en el infrarrojo medio. Los índices y componentes de transformación en cuyos cálculos se utilizan las bandas corregidas 1, 2 y 3, no pudieron obtenerse debido a la corrección no satisfactoria antes mencionada. Debido a lo anterior, dichos índices y componentes fueron calculados sólo en base a los valores digitales (bandas sin corrección radiométrica). El índice IRVI, que considera las bandas 4 y 5, se pudo calcular a partir de las bandas corregidas y se denominó IRVIC.

Con el fin de evaluar la posibilidad de establecer relaciones entre la edad de las plantaciones y los valores digitales, sin corregir radiometría, se utilizaron también las bandas no corregidas. Para trabajar se generó un conjunto de coberturas que incluyó las bandas 1-5,7 de Landsat TM5 sin corregir, bandas 1-5,7 de Landsat TM5 corregidas, B, G, W, SRVI, NDVI, IRVI e IRVIC.

Edad de plantaciones e información espectral. La información de las edades de las plantaciones estudiadas se obtuvo a partir de datos suministrados por la SAGPyA provenientes del primer inventario nacional de plantaciones realizado en 1998, del Sistema de Promoción de la SAGPyA y datos provistos por diferentes empresas. Se estratificó la información por género en eucalipto y pino. Para los análisis de regresión, se seleccionaron al azar plantaciones (representación en polígonos) tratando de cubrir de forma homogénea todo el rango de edades, siendo de 4 a 12 años para eucalipto y de 4 a 27 años para pino. Durante la selección se tuvo en cuenta que los polígonos muestra fueran representativos y homogéneos dentro de su superficie. Para eucalipto se analizaron 39 polígonos y para pino 73 polígonos (cuadro 1).

Sobre los polígonos muestra se consideró una zona buffer que consistió en una faja de $60 \mathrm{~m}$ desde el límite de cada polígono hacia adentro. Esta faja se eliminó del polígono y se generaron los nuevos polígonos muestra, eliminando así el efecto del borde de la plantación sobre los valores espectrales medios del polígono (figura $3 \mathrm{a}$ ). Este proceso se realizó con el programa Arc View. Con el programa Erdas Imagine, se convirtieron estos polígonos

Cuadro 1. Distribución de polígonos por edad y género. Sample polygons and their distribution by age and genera.

\begin{tabular}{|c|c|c|c|c|c|}
\hline \multicolumn{4}{|c|}{ Pinus spp. } & \multicolumn{2}{|c|}{ Eucalyptus spp. } \\
\hline $\begin{array}{c}\text { Edad } \\
\text { (años) }\end{array}$ & $\begin{array}{c}\mathrm{N}^{\mathrm{o}} \\
\text { Polígonos }\end{array}$ & $\begin{array}{l}\text { Edad } \\
\text { (años) }\end{array}$ & $\begin{array}{c}\mathrm{N}^{\mathrm{o}} \\
\text { Polígonos }\end{array}$ & $\begin{array}{c}\text { Edad } \\
\text { (años) }\end{array}$ & $\begin{array}{c}\mathrm{N}^{\mathrm{o}} \\
\text { Polígonos }\end{array}$ \\
\hline 4 & 7 & 16 & 2 & 4 & 4 \\
\hline 5 & 4 & 17 & 4 & 5 & 6 \\
\hline 6 & 4 & 18 & 3 & 6 & 5 \\
\hline 7 & 3 & 19 & 3 & 7 & 6 \\
\hline 8 & 2 & 20 & 3 & 8 & 3 \\
\hline 9 & 3 & 21 & 3 & 9 & - \\
\hline 10 & 3 & 22 & 3 & 10 & 1 \\
\hline 11 & 3 & 23 & 1 & 11 & 10 \\
\hline 12 & 3 & 24 & 3 & 12 & 4 \\
\hline 13 & 2 & 25 & 3 & & \\
\hline 14 & 3 & 26 & 3 & & \\
\hline 15 & 3 & 27 & 2 & & \\
\hline & Total & & 73 & Total & 39 \\
\hline
\end{tabular}



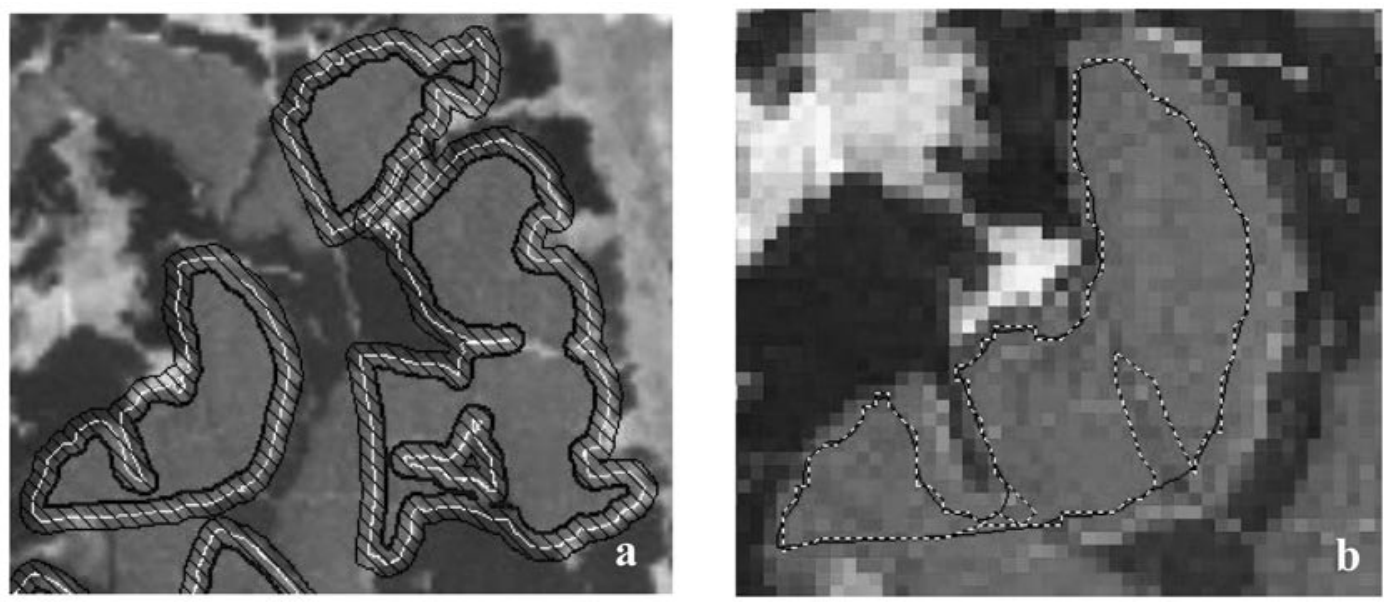

Figura 3. a) Plantaciones de Eucalyptus spp. donde se observan los límites originales de los polígonos (línea delgada clara) y los límites remanentes (línea gruesa oscura) luego de descontar $60 \mathrm{~m}$ desde el límite original del polígono hacia adentro, aplicando una zona buffer de $120 \mathrm{~m}$ de ancho (rayado oscuro) alrededor del mismo. b) La línea delgada oscura representa el límite del polígono una vez descontada la zona buffer. La línea punteada delimita el AOI (área de interés) que realmente se tomó como muestra. Se muestra una parte descontada por el AOI correspondiente a un claro en la plantación.

a) Eucalyptus spp. plantations, where the borderline of the original polygon is shown (thin light line) together with the borderline remaining (thick dark line) after discounting $60 \mathrm{~m}$ from the original polygon borderline inwards, by applying a $120 \mathrm{~m}$ wide buffer area (striped) around it. b) Sample polygon where the thin dark line represents the polygon border having deducted the buffer area. The dashed line shows the AOI (area of interest) that was sampled, not taking into account clearings in the stand canopy.

a AOI (area of interest) para luego convertir los valores de píxel incluidos en los mismos a formato ASCII, generándose así una planilla de datos con los valores por píxel de todas las bandas del conjunto de coberturas. En este proceso se excluyeron de los AOI los claros, para evitar la influencia de los valores espectrales de los mismos en la media del polígono (figura $3 b$ ).

Análisis de datos. Se analizaron los datos de eucalipto y pino por separado. Para cada género se calcularon los valores medios de las diferentes bandas por polígono, y esto constituyó la base de datos (cuadro 2). Previo al análisis de los datos se realizó una prueba de normalidad de los mismos, para evitar posibles suposiciones erróneas acerca de la distribución de los mismos y determinar de esta forma la metodología de análisis a seguir. Considerando el tamaño pequeño de las muestras se utilizó la prueba de Shapiro-Wilk para determinar objetivamente si la distribución de los datos seguía una distribución normal, según recomienda Park (2003).

El primer paso en el análisis fue el estudio de las relaciones entre las diferentes variables explicatorias (bandas de Landsat TM5 corregidas y sin corregir, índices de vegetación) y la variable de respuesta (edad) (cuadro 2). Esto se realizó mediante un análisis de correlación cruzado de todas las variables contra todas, analizando los valores de significancia a un nivel de probabilidad $(P)$ y coeficiente de correlación de Pearson (r) para cada posibilidad. Además se graficaron cada una de las variables contra las demás para tener una interpretación gráfica de la correlación existente, así como una imagen del tipo de relación entre cada una de las variables explicatorias y la de respuesta.

Se identificaron las variables explicatorias significativamente correlacionadas con la variable de respuesta, con un nivel de probabilidad de $P<0,05$. Por medio de un análisis de regresión múltiple, se construyeron ecuaciones tratando de no incluir en ellas variables explicatorias correlacionadas significativamente entre sí, con una probabilidad de $P<0,05$. Para la inclusión o no de las variables explicatorias dentro de las ecuaciones, se tuvo en cuenta que explicaran la variabilidad de la edad con un $99 \%$ de probabilidad $(P<0,01)$.

Cuadro 2. Variables utilizadas para los análisis de correlación y de regresión.

Variables used for correlation and regression analyses.

\begin{tabular}{llll}
\hline Variable* $^{*}$ & Abreviatura & Variable* & Abreviatura \\
\hline Edad & edad & Banda 4 c & BC4 \\
Banda 1 sc & B1 & Banda 5 c & BC5 \\
Banda 2 sc & B2 & Banda 7 c & BC7 \\
Banda 3 sc & B3 & Greenness & G \\
Banda 4 sc & B4 & Brightness & B \\
Banda 5 sc & B5 & Wetness & W \\
Banda 7 sc & B7 & Simple Ratio VI & SRVI \\
Banda 1 c & BC1 & Normalized difference VI & NDVI \\
Banda 2 c & BC2 & Infra Red VI & IRVI \\
Banda 3 c & BC3 & & \\
\hline
\end{tabular}


Para el caso en que la distribución de puntos entre las variables explicatorias y la de respuesta presentó heterocedasticidad, se probaron diferentes transformaciones tendientes a que la curva de regresión se ajustara mejor a los datos (Ramsey y Shafer 1997). Cuando al analizar dichas relaciones individuales surgieron valores anormales (outliers), se analizó en detalle cada uno de éstos, para ver el motivo de su desvío y así se determinó su inclusión o no en la muestra.

Para evaluar la calidad de ajuste y seleccionar la mejor ecuación, se utilizó el coeficiente de determinación $\left(\mathrm{r}^{2}\right)$, la raíz del error medio cuadrático (RMSE) [1] y el valor en porcentaje de este último [2].

$$
\begin{aligned}
R M S E & =\sqrt{\sum(o-e)^{2} / n} \\
R M S E \% & =(R M S E * 100) / \mathrm{O}
\end{aligned}
$$

donde: RMSE $=$ raíz del error cuadrático medio, $\mathrm{o}=$ observado, $\mathrm{e}=$ estimado, $\mathrm{n}=$ número de observaciones, $\hat{\mathrm{O}}=$ media de valores observados.

Como una medida de sesgo se utilizaron la diferencia agregada (DIFA) [3] y el valor porcentual de la misma [4], y tener así un indicador de si el modelo sobre o subestima:

$$
\begin{gathered}
D I F A=\sum(o-e) / n \\
D I F A \%=(|D I F A| * 100) / \hat{O}
\end{gathered}
$$

donde: DIFA $=$ diferencia agregada, $\mathrm{o}=$ observado, $\mathrm{e}=$ estimado, $\mathrm{n}=$ número de observaciones, $\hat{\mathrm{O}}=$ media de valores observados.

Las ecuaciones con transformaciones se compararon mediante el índice de Furnival (Furnival 1961) [5], ya que permite evaluar modelos donde la variable dependiente $\mathrm{Y}^{\prime}$ representa diferentes transformaciones de la variable original Y. Este índice no sólo permite estimar el tamaño de los residuales, sino que también refleja la posible falta de linearidad, normalidad y homocedasticidad (Furnival 1961).

$$
I F=\exp \left[\frac{\sum \ln \left[f^{\prime}(Y)\right]^{-1}}{n}\right] * \sqrt{M S E}
$$

donde: $\mathrm{IF}=$ índice de Furnival, $\mathrm{n}=$ número de observaciones, MSE $=$ error medio cuadrático, $f^{\prime}(Y)=$ derivada primera respecto de $\mathrm{Y}$ de la transformación $\mathrm{Y}^{\prime}$.

Validación. Las ecuaciones seleccionadas para pino y eucalipto se validaron sobre una muestra independiente de polígonos. Se intentó que ésta incluyera polígonos de todo el rango de edades para cada género. Para pino se seleccionaron 14 polígonos y para eucalipto 35 polígonos. A partir de esta muestra independiente se compararon los valores predichos con los observados, calculándose una media de los desvíos.

\section{RESULTADOS}

Correlación entre variables. Del análisis de correlación efectuado se seleccionaron las variables que presentaron una correlación significativa $(P<0,05)$ con la edad (cuadro 3) para eucalipto y pino. En ambos casos todas las relaciones entre variables explicatorias y la edad que resultaron significativas fueron inversas. Para eucalipto se encontró una alta correlación entre la banda 4 , tanto corregida $(r=-0,58)$ como sin corregir $(r=-0,63)$, y la edad. Los índices de vegetación de SRVI, NDVI, B y G también mostraron una relación significativa con la edad, sin embargo se debe tener en cuenta que tales índices en su cálculo presentan gran influencia de la banda 4. En pino, la edad estuvo correlacionada con un mayor número de variables explicatorias. En este caso, la relación fue significativa principalmente para la banda 4 corregida $(\mathrm{r}=-0,79)$ y $\sin$ corregir $(\mathrm{r}=-0,80)$. Además existió una relación significativa entre la edad y la banda 5 corregida, como así también con las bandas 1,2 y 5 sin corregir radiométricamente. Sin embargo el coeficiente de correlación para estas últimas fue menor (cuadro 3). Los índices de vegetación para pino fueron todos significativos en su relación con la edad, presentando un mayor coeficiente de correlación los mismos que resultaron significativos para el género Eucalyptus (SRVI, NDVI, B y G) (cuadro 3).

Es importante resaltar la alta correlación entre algunas de las variables explicatorias. Se observó una alta correlación entre las bandas bc4 y b4 y entre las bandas bc5 y b5 para ambos géneros. Las bandas 4 y 5 resultaron además muy correlacionadas con los índices de vegetación, debido a que la mayoría de ellos se calcularon a partir de dichas bandas con mayor o menor participación (cuadro 4).

Analizando los gráficos de distribución de puntos para las relaciones entre variables explicatorias y la edad para eucalipto, se observó que en el caso de b4, bc4 y g resultaron ser inversas y con una tendencia no lineal. También se observó una leve heterocedasticidad, lo que indicó la necesidad de una transformación. En el caso del pino, la distribución de la nube de puntos de las relaciones entre variables explicatorias, mejor correlacionadas, y la edad, presentó en todos los casos una tendencia más lineal.

Análisis de regresión. Tomando los resultados del análisis de correlación para eucalipto, se realizaron regresiones lineales entre edad y las bandas bc4, b4 y g (cuadro 3). Las restantes variables, correspondientes a índices de vegetación no se incluyeron en las regresiones, ya que presentaron una alta correlación entre sí y con la banda 4 (bc4 y b4). Teniendo en cuenta la presencia de heterocedasticidad en la tendencia curvilínea de la distribución de puntos al graficar la variable de respuesta versus explicatorias, se realizaron transformaciones de las variables siguiendo las recomendaciones de Ramsey y Shafer (1997). Con esto se ajustaron tres tipos de ecuaciones: lineales logarítmicas, lineales no logarítmicas y no lineales (cuadro 5). 
Cuadro 3. Coeficientes de correlación (r) y respectivo valor de probabilidad $(P)$ entre las variables explicatorias y la variable de respuesta edad para Eucalyptus spp. (Euc.) y Pinus spp. (Pin.).

Correlation coefficients (r) and their respective probability values $(P)$, between independent variables and dependent variable age for Eucalyptus spp. and Pinus spp.

\begin{tabular}{ccccccccccccccc}
\hline Especie & & B1 & B2 & B4 & B5 & BC4 & BC5 & SRVI & NDVI & IRVI & IRVIC & B & G & W \\
\hline \multirow{2}{*}{ Euc. } & $\mathrm{r}$ & & & $-0,63$ & & $-0,58$ & & $-0,56$ & $-0,55$ & & & $-0,54$ & $-0,63$ & \\
& $P$ & & & $<0,0001$ & & $<0,0001$ & & 0,0002 & 0,0003 & & & 0,0005 & $<0,0001$ & $-0,00$ \\
\hline \multirow{2}{*}{ Pin. } & $\mathrm{r}$ & $-0,32$ & $-0,35$ & $-0,80$ & $-0,30$ & $-0,79$ & $-0,26$ & $-0,72$ & $-0,71$ & $-0,44$ & $-0,48$ & $-0,80$ & $-0,78$ & $-0,42$ \\
& $P$ & 0,0075 & 0,003 & $<0,0001$ & 0,012 & $<0,0001$ & 0,033 & $<0,0001<0,0001$ & 0,0001 & $<0,0001<0,0001<0,0001$ & 0,0004 \\
\hline
\end{tabular}

Cuadro 4. Coeficientes de correlación entre variables explicatorias y sus niveles de significancia para Eucalyptus spp. (a) y Pinus spp. (b).

Correlation coefficients between independent variables and their significance levels for Eucalyptus spp. (a) and Pinus spp. (b).

\begin{tabular}{cllllll|l}
\hline B4 & BC4 & SRVI & NDVI & B & G & W & \\
\hline 1 & $0,92^{* *}$ & $0,88^{* *}$ & $0,88^{* *}$ & $0,75^{* *}$ & $0,98^{* *}$ & $0,63^{* *}$ & B4 \\
& 1 & $0,77^{* *}$ & $0,76^{* *}$ & $0,75^{* *}$ & $0,88^{* *}$ & $0,53^{* *}$ & BC4 \\
& & 1 & $0,99^{* *}$ & $0,37^{*}$ & $0,95^{* *}$ & $0,86^{* *}$ & SRVI \\
& & & 1 & $0,35^{*}$ & $0,95^{* *}$ & $0,86^{* *}$ & NDVI \\
& & & & 1 & $0,63^{* *}$ & - & B \\
(a) & & & & & 1 & $0,72^{* *}$ & G \\
\hline
\end{tabular}

\begin{tabular}{|c|c|c|c|c|c|c|c|c|c|c|c|c|c|}
\hline B1 & B2 & B4 & B5 & $\mathrm{BC} 4$ & BC5 & SRVI & NDVI & IRVI & IRVIC & B & G & W & \\
\hline (b) & $\begin{array}{l}0,80 * * \\
1\end{array}$ & $\begin{array}{l}- \\
0,31 * * \\
1\end{array}$ & $\begin{array}{c}0,48^{* *} \\
0,71^{* *} \\
- \\
1\end{array}$ & $\begin{array}{c}- \\
0,25^{*} \\
0,80^{* *} \\
- \\
1\end{array}$ & $\begin{array}{c}0,32^{* *} \\
0,46^{* *} \\
- \\
0,71^{* *} \\
- \\
1\end{array}$ & $\begin{array}{l}- \\
- \\
0,95^{* *} \\
- \\
0,77^{* *} \\
- \\
1\end{array}$ & $\begin{array}{l}- \\
- \\
0,93 * * \\
- \\
0,79 * * \\
- \\
0,99 * * \\
1\end{array}$ & $\begin{array}{r}- \\
- \\
0,75^{* *} \\
-0,60^{* *} \\
0,60^{* *} \\
-0,50^{* *} \\
0,88^{* *} \\
0,88^{* *} \\
1\end{array}$ & $\begin{array}{c}- \\
- \\
0,69^{* *} \\
-0,35^{* *} \\
0,80^{* *} \\
-0,58^{* *} \\
0,77^{* *} \\
0,80^{* *} \\
0,81^{* *} \\
1\end{array}$ & $\begin{array}{l}0,50^{* *} \\
0,68^{* *} \\
0,87^{* *} \\
0,53^{* *} \\
0,72^{* *} \\
0,30^{* *} \\
0,68^{* *} \\
0,66^{* *} \\
0,35^{* *} \\
0,41^{* *} \\
1\end{array}$ & $\begin{array}{l}- \\
- \\
0,99^{* *} \\
- \\
0,79^{* *} \\
- \\
0,98^{* *} \\
0,97^{* *} \\
0,81^{* *} \\
0,73^{* *} \\
0,80^{* *} \\
1\end{array}$ & $\begin{array}{r}- \\
- \\
- \\
0,72 * * \\
-0,63 * * \\
0,54 * * \\
-0,51 * * \\
0,84 * * \\
0,84 * * \\
0,99 * * \\
0,77 * * \\
0,32 * * \\
0,77 * * \\
1\end{array}$ & $\begin{array}{l}\text { B1 } \\
\text { B2 } \\
\text { B4 } \\
\text { B5 } \\
\text { BC4 } \\
\text { BC5 } \\
\text { SRVI } \\
\text { NDVI } \\
\text { IRVI } \\
\text { IRVIC } \\
\text { B } \\
\text { G } \\
\text { W }\end{array}$ \\
\hline
\end{tabular}

Cuadro 5. Ecuaciones ajustadas para Eucalyptus spp., utilizando las variables mejor correlacionadas con la edad (B4: banda 4, BC4: banda corregida 4 y G: greenness) para la imagen Landsat TM5, 224-080, del 17 de enero de 2005. (Log.: logarítmicas; RMSE: raíz del error medio cuadrático; IF: índice de Furnival).

Equations adjusted for Eucalyptus spp., using the best correlated variables with age (B4: band 4, BC4: corrected band 4 and G: greenness). For Landsat TM 5, 224-080, captured on 17th January 2005. (Log.: Logarithmic; RMSE: Root Mean Square Error; IF: Furnival's Index).

\begin{tabular}{|c|c|c|c|c|c|c|c|}
\hline \multirow{2}{*}{ Tipo de Ecuación } & \multirow{2}{*}{ Ecuación } & \multicolumn{2}{|c|}{$\mathrm{X}=\mathrm{b} 4$} & \multicolumn{2}{|c|}{$X=b c 4$} & \multicolumn{2}{|c|}{$X=g$} \\
\hline & & RMSE & IF & RMSE & IF & RMSE & IF \\
\hline \multirow[t]{2}{*}{ Lineales Log. } & $\log _{10} E=a+b * X$ & 0,124 & 2,129 & 0,129 & 2,216 & 0,126 & 2,160 \\
\hline & $\log _{10} E=a+b * \log _{10} X$ & 0,125 & 2,139 & 0,130 & 2,232 & 0,127 & 2,179 \\
\hline Lineal no Log. & $\sqrt[2]{E}=a+b * X$ & 0,394 & 2,171 & 0,411 & 2,265 & 0,397 & 2,188 \\
\hline \multirow[t]{2}{*}{ No Lineales } & $E=10^{a+b * X}$ & 2,283 & 2,283 & 2,387 & 2,387 & 2,282 & 2,282 \\
\hline & $E=10^{a} * X^{b}$ & 2,299 & 2,299 & 2,408 & 2,408 & 2,311 & 2,311 \\
\hline
\end{tabular}


Se consideraron las ecuaciones lineales no logarítmicas para los tres casos (cuadro 5) para evitar el sesgo intrínseco de las ecuaciones logarítmicas. Los valores de IF fueron levemente mayores para las lineales no logarítmicas pero en ningún caso superan el $3 \%$ con respecto a las lineales logarítmicas (f(bc4): 1,92\% f(b4): 2,15\% y f(g): 1,27\%) (cuadro 5). Se eligieron finalmente 2 ecuaciones en base a los valores de la banda 4, con coeficientes de determinación del $39,6 \%$ y $34,4 \%$ para valores sin corregir y corregidos respectivamente (cuadro 6). La ecuación utilizando el G se dejó de lado debido a la mayor complejidad para su cálculo, al hecho de que no aportó mejoras significativas en las estimaciones y a que sólo se lo puede calcular en base a bandas no corregidas radiométricamente. En la figura 4 se presentan los gráficos de residuales para las ecuaciones seleccionadas, en los que se puede observar una adecuada distribución de los residuos para los dos casos, sin tendencias ni datos anormales.

De la misma forma que para eucalipto, se construyeron ecuaciones lineales con las variables significativamente correlacionadas con la edad. En el caso del pino se pudieron construir ecuaciones con más de una variable independiente, logrando con esto una mejor explicación de la variabilidad de la edad. Se realizó un análisis de regresión múltiple con el método "stepwise" para la selección de variables, con un nivel de probabilidad $P<0,01$.

$\mathrm{Se}$ analizaron primero las bandas individuales no corregidas correlacionadas con la edad, a pesar de que algunas de éstas estuvieran correlacionadas entre sí. Luego se probaron de la misma manera los índices de vegetación y por último cada uno de los índices de vegetación con las bandas no corregidas que no estuvieran correlacionadas con cada índice. Para el caso de las bandas corregidas primero se analizaron las bandas individuales y luego se analizó por separado el índice de vegetación (IRVIC) calculado a partir de las mismas.

A diferencia del análisis para eucalipto, no fue necesaria una transformación de variables, ya que la relación entre la edad y las distintas variables explicatorias fue básicamente una recta y no se observó heterocedasticidad. En algunos casos como b4, g y b se observó mayor variabilidad para valores bajos y altos de edad, con menor variación en los valores medios de dicha variable. Se ajustaron 10 ecuaciones lineales, dos de las cuales fueron simples y las restantes múltiples (cuadro 7).

Teniendo en cuenta la simplicidad de la ecuación y las diferencias mínimas de los valores de RMSE y $\mathrm{r}^{2}$ se seleccionaron dos ecuaciones para pino, basadas en las bandas 4 y 5 corregidas y no corregidas radiométricamente. Dichas ecuaciones permiten estimar la edad en función de las bandas 4 y 5 con un $\mathrm{R}^{2}$ de $70 \%$ con dichas bandas sin corregir y de $68 \%$ en función de las bandas corregidas. Los residuales de las ecuaciones seleccionadas se presentan en la figura 5, y ninguno de los dos casos mostró tendencias.
Los valores negativos de la DIFA indicaron que ambas ecuaciones subestimaron levemente (cuadro 8).

Como para el caso de eucalipto, la ecuación en función de bandas no corregidas tiene una aplicación específica, mientras que la ecuación sobre la base de las bandas corregidas podría aplicarse a diferentes imágenes.

Cuadro 6. Ecuaciones seleccionadas para Eucalyptus spp. para la imagen Landsat TM5, 224-080, del 17 de enero de 2005. (RMSE: raíz del error medio cuadrático; IF: índice de Furnival; Adj $\mathrm{R}^{2}: \mathrm{R}^{2}$ ajustado).

Selected equations for Eucalyptus spp. using Landsat TM5, 224-080 image captured 17 th January 2005. (RMSE: Root Mean Square Error; Adj. R²: Adjusted R²; DIFA: added difference).

\begin{tabular}{cccc}
\hline Ecuación & RMSE & IF & Adj R \\
\hline$\sqrt[2]{E}=8,32114-0,05584 * B 4$ & 0,394 & 2,171 & 0,396 \\
$\sqrt[2]{E}=7,04743-0,02641 * B C 4$ & 0,411 & 2,265 & 0,344 \\
\hline
\end{tabular}
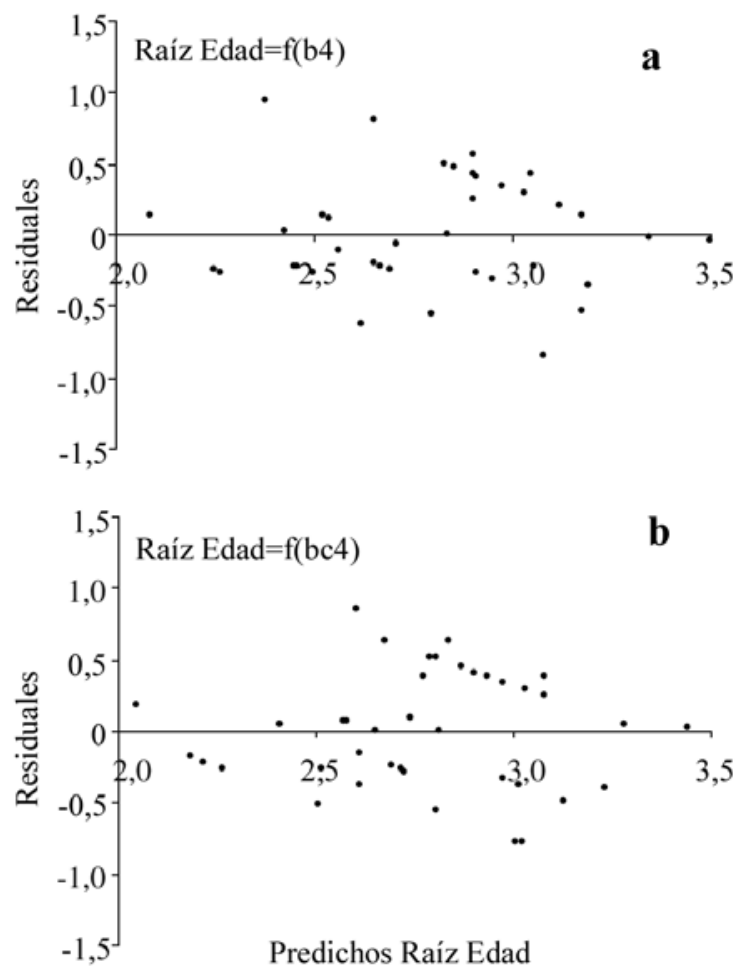

Figura 4. Distribución de valores residuales de las funciones seleccionadas para Eucalyptus spp. a) Residuales de la raíz cuadrada de la edad en función de la banda 4 (raíz edad = f (b4)) y b) residuales de la raíz cuadrada de la edad en función de la banda corregida 4 (raíz edad $=\mathrm{f}(\mathrm{bc} 4)$ ).

Residuals of equations selected for Eucalyptus spp. a) Residuals of the square root of the age as a function of band 4 (raíz edad $=\mathrm{f}(\mathrm{b} 4))$. b) Residuals of the square root of the age as a function of corrected band 4 (raíz edad = f (bc4)). 
Cuadro 7. Ecuaciones ajustadas para Pinus spp. para la imagen Landsat 5, 224-080, del 17 de enero de 2005. (RMSE: raíz del error medio cuadrático; Adj $\mathrm{R}^{2}$ : $\mathrm{R}^{2}$ ajustado; DIFA: diferencia agregada).

Equations adjusted for Pinus spp. using Landsat TM5, 224-080 image captured 17th January 2005. (RMSE: Root Mean Square Error; Adj. $\mathrm{R}^{2}$ : Adjusted $\mathrm{R}^{2}$; DIFA: added difference).

\begin{tabular}{|c|c|c|c|c|c|}
\hline $\begin{array}{r}\text { Ecuación } \\
\end{array}$ & RMSE & RMSE \% & Adj $R^{2}$ & DIFA & DIFA $\%$ \\
\hline$E=a+b * B 4+c * B 5$ & 4,03 & 27,84 & 0,70 & $-0,00002319$ & 0,000160 \\
\hline$E=a+b * B+c * N D V I$ & 4,04 & 27,87 & 0,69 & $-0,00005529$ & 0,000382 \\
\hline$E=a+b * W+c * B 2$ & 5,91 & 40,85 & 0,34 & 0,00000617 & 0,000043 \\
\hline$E=a+b * G+c * B 5$ & 4,04 & 27,89 & 0,69 & $-0,00000898$ & 0,000062 \\
\hline$E=a+b * B$ & 4,37 & 30,19 & 0,64 & $-0,00041469$ & 0,002864 \\
\hline$E=a+b * I R V I+c * B 2$ & 5,68 & 39,25 & 0,39 & $-0,00001025$ & 0,000071 \\
\hline$E=a+b * N D V I+c * B 1+d * B 5$ & 3,80 & 26,24 & 0,73 & 0,00018885 & 0,001304 \\
\hline$E=a+b * S R V I+c * B 5$ & 3,98 & 27,49 & 0,70 & 0,00010912 & 0,000754 \\
\hline$E=a+b * B C 4+c * B C 5$ & 4,15 & 28,69 & 0,68 & $-0,00033910$ & 0,002342 \\
\hline$E=a+b * I R V I C$ & 6,44 & 44,45 & 0,22 & 0,00000018 & 0,000001 \\
\hline
\end{tabular}

Cuadro 8. Ecuaciones seleccionadas para Pinus spp. para la imagen Landsat 5, 224-080, del 17 de enero de 2005. (RMSE: raíz del error medio cuadrático; Adj $\mathrm{R}^{2}$ : $\mathrm{R}^{2}$ ajustado; DIFA: diferencia agregada).

Selected equations for Pinus spp. using Landsat TM5, 224-080 image captured 17th January 2005. (RMSE: Root Mean Square Error; Adj $R^{2}$ : Adjusted $R^{2}$; DIFA: added difference).

\begin{tabular}{lccccc}
\hline \multicolumn{1}{c}{ Ecuación } & RMSE & RMSE $\%$ & Adj R & DIFA & DIFA \% \\
\hline$E=95,00011-0,77174 * B 4-0,56391 * B 5$ & 4,03 & 27,84 & 0,70 & $-0,00002$ & 0,00016 \\
$E=79,70793-0,39718 * B C 4-0,41287 * B C 5$ & 4,15 & 28,69 & 0,68 & $-0,0003$ & 0,0023 \\
\hline
\end{tabular}
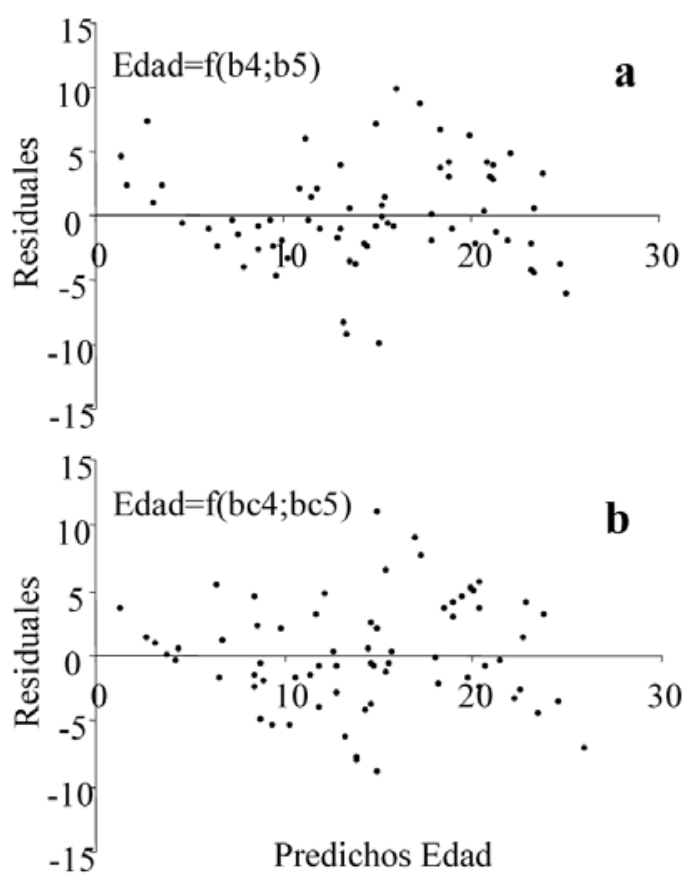

Figura 5. Distribución de valores residuales de las funciones seleccionadas para Pinus spp. a) Residuales de la ecuación que estima edad en función de las bandas 4 y 5 sin corregir $(\mathrm{Edad}=\mathrm{f}(\mathrm{b} 4 ; \mathrm{b} 5))$ y b) Residuales de la ecuación que estima la edad en función de las bandas 4 y 5 corregidas $(\mathrm{Edad}=\mathrm{f}(\mathrm{bc} 4$; bc5)).

Residuals of equations selected for Pinus spp. a) Residuals of the equation that estimates age as a function of non corrected bands 4 and $5(\operatorname{Edad}=\mathrm{f}(\mathrm{b} 4 ; \mathrm{b} 5))$. b) Residuals of the equation that estimates age as a function of corrected bands 4 and $5(E d a d=f(b c 4 ; b c 5))$.
Validación de modelos. Al probar las ecuaciones elegidas con datos independientes de la muestra para su validación, los errores medios entre las ecuaciones en base a bandas sin corregir y corregidas fueron de 2,16 años para eucalipto y de 3,52 años en pino (cuadro 9). Las ecuaciones ajustadas para eucalipto subestimaron la edad de las plantaciones de más de 11 años (figuras 6 y 7). No se dispuso, para eucalipto, con edades intermedias para la prueba. Con respecto al pino, las ecuaciones sobreestimaron en general la edad de plantaciones tempranas (4 a 10 años), y subestimaron la edad de plantaciones de 21 y 24 años (figura 8).

Cuadro 9. Resultados de la prueba de los modelos sobre polígonos independientes a la muestra y valores medios del error.

Results of testing the equations on the independent polygons and the mean error values.

\begin{tabular}{llc}
\hline Género & Ecuación & $\begin{array}{c}\text { Media } \\
\text { del error } \\
(\text { años })\end{array}$ \\
\hline Eucalyptus & $\sqrt[2]{E}=8,32114-0,05584 * B 4$ & 2,13 \\
& $\sqrt[2]{E}=7,04743-0,02641 * B C 4$ & 2,19 \\
\hline Pinus & $E=95,00011-0,77174 * B 4-0,56391 * B 5$ & 3,46 \\
& $E=79,70793-0,39718 * B C 4-0,41287 * B C 5$ & 3,57 \\
\hline
\end{tabular}



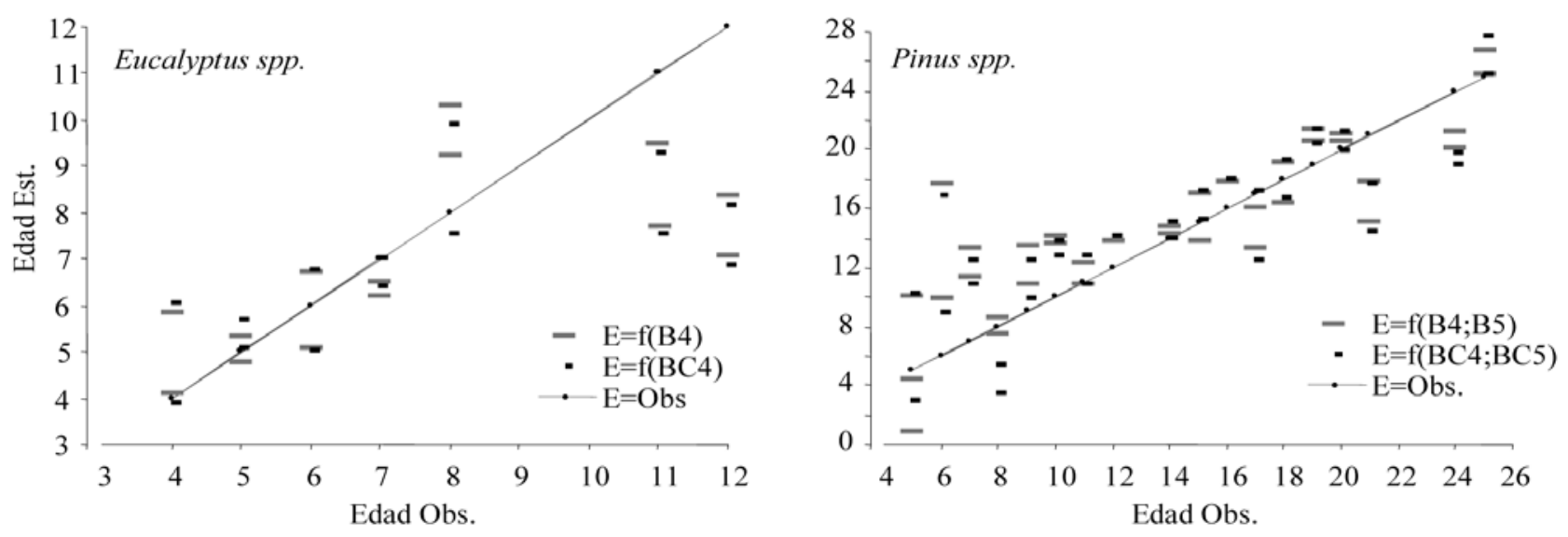

Figura 6. Valores observados (Obs.) (línea gris) y estimados (Est.) al ajustar las ecuaciones seleccionadas para Eucalyptus spp. y Pinus spp. a la muestra de plantaciones seleccionadas para su validación. Las líneas cortas y negras representan la estimación de la edad (E) en función de las bandas corregidas (BC4; BC5) y las líneas largas y grises estimaciones de la edad (E) en función de las bandas no corregidas (B4; B5).

Observed (Obs.) (grey line) and estimated values (Est.) after the adjusted equations on polygons left aside for validation were tested. Short black dashes represent values of corrected band equations and long grey dashes non corrected band equations.
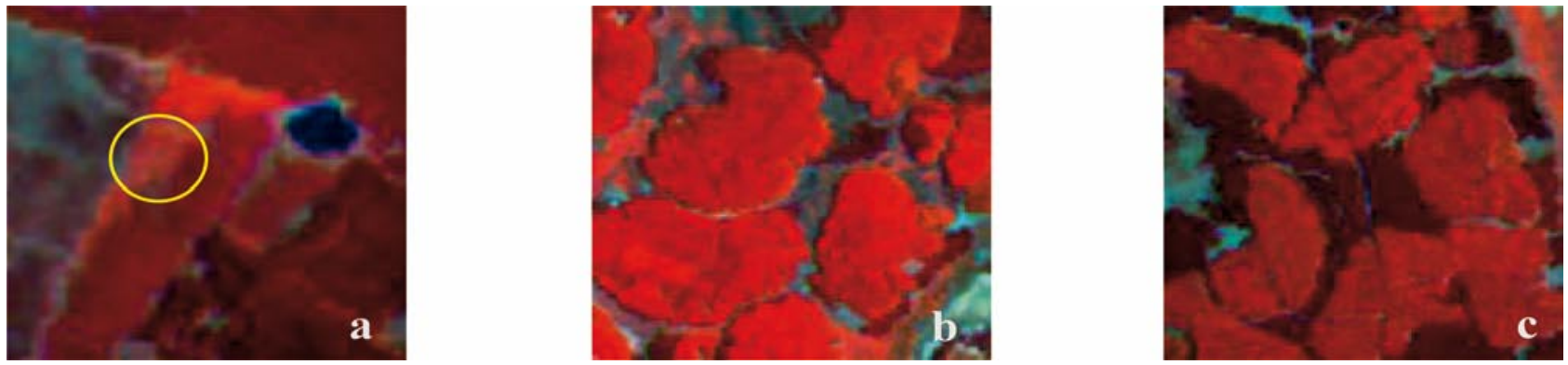

Figura 7. Quick looks de plantaciones de Eucalyptus spp. en las tres clases de edad en una combinación de bandas 4-5-3 en R-GB. a) $<4$ años, b) 4 a 8 años y c) 8 a 12 años.

Quick looks of Eucalyptus spp. stands in 3 age classes. Band combination 4-5-3 on R-G-B. a) < 4 years old, b) 4 to 8 years old and c) 8 to 12 years old.
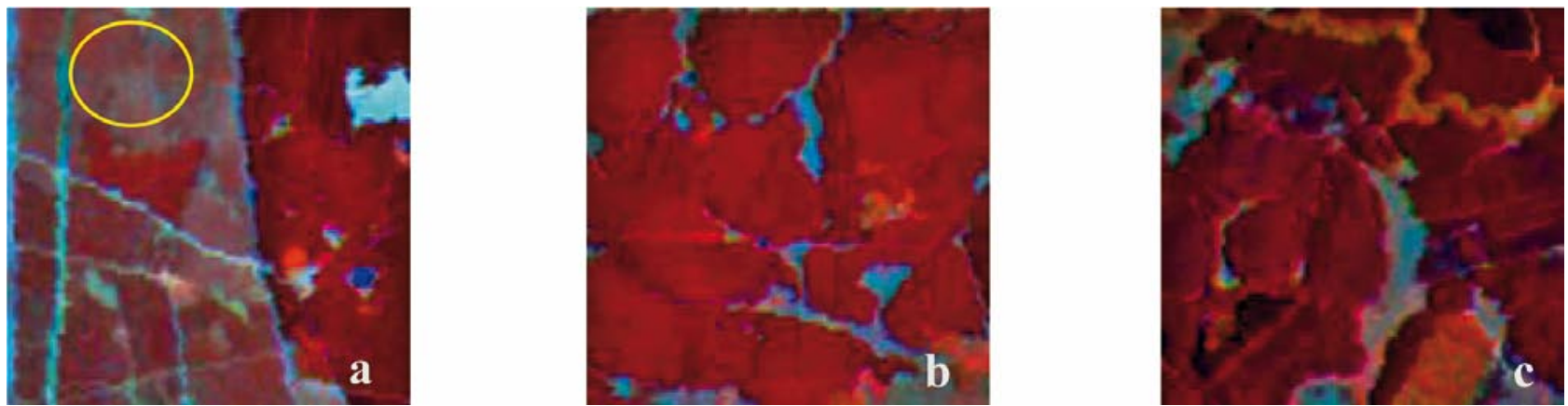

Figura 8. Quick looks de plantaciones de Pinus spp. en las tres clases de edad en una combinación de bandas 4-5-3 en R-G-B. a) $<4$ años, b) 4 a 15 años y c) 15 a 26 años.

Quick looks of Pinus spp. stands in three age classes. Band combination 4-5-3 on R-G-B. a) < 4 years old, b) 4 to 15 years old and c) 15 to 26 years old. 


\section{DISCUSIÓN}

Las relaciones significativas encontradas en este estudio entre las variables explicatorias y la edad son inversas para ambos géneros. Esta relación inversa entre valores espectrales y la edad fue reportada para plantaciones de coníferas en investigaciones de Danson y Curran (1993), Niemann (1995), Cohen et al. (1995), Jensen et al. (1999) y Sivanpillai et al. (2006).

Los valores de coeficientes de correlación determinados en el presente estudio entre el índice NDVI y la banda 4 con la edad son similares a los encontrados por Jensen et al. (1999), quienes al analizar la relación entre valores espectrales de Landsat 5 y edad de plantaciones de $P$. taeda en Brasil, determinaron coeficientes de correlación de valores de $-0,51$ y $-0,87$ para la correlación entre índice NDVI y banda 4 , respectivamente.

Con respecto a la tendencia lineal encontrada para los datos de pino, difiere con los resultados obtenidos en otras investigaciones con plantaciones de coníferas, ya que en general éstas mostraron una relación más bien no lineal entre la edad y los valores espectrales (Cohen et al. 1995, Jensen et al. 1999). Sin embargo, Sivanpillai et al. (2006) determinaron una relación lineal entre la edad y los valores espectrales de la banda 4 de Landsat 7 para $P$. taeda.

De los resultados del análisis de regresión para eucalipto se observa que las ecuaciones que mejor ajustan son en los tres casos (edad en función de b4, bc4 y g) modelos lineales logarítmicos, al analizar los respectivos valores del IF (cuadro 5). Bell et al. (1981) demostraron que aunque las ecuaciones lineales logarítmicas presenten un IF levemente menor al de las ecuaciones no lineales equivalentes, estas últimas son preferibles, ya que no incluyen el sesgo intrínseco de las ecuaciones logarítmicas. Algunos autores aseguran que cuando el objetivo es hacer predicciones este sesgo puede estar en el orden de un $10 \%$ a un 20\% (Baskerville 1972).

En cuanto a las ecuaciones ajustadas para pino en este trabajo, Sivanpillai et al. (2006) obtuvieron resultados similares, al seleccionar una función de regresión lineal integrando las bandas 4 y 7 (infrarrojo cercano y medio respectivamente) para la estimación de edad de P. taeda sobre la base de datos satelitales Landsat 7, obteniendo un coeficiente $\mathrm{R}^{2}$ de $68,2 \%$. En cuanto a las variables extraídas de bandas sintéticas, la combinación del NDVI, el cociente TM4/TM3 y el B de tasseled cap entregó los resultados más satisfactorios para la estimación de la edad de P. taeda.

Trabajos de Donoghue et al. (2002) para Picea sitchensis (Bong.) Carr. han demostrado una alta correlación entre las bandas del infrarrojo cercano y medio de Landsat 7 y SPOT 4 con la edad de los rodales $\left(\mathrm{R}^{2}\right.$ entre $-0,69$ y $-0,74)$ con error estándar inferior a 2,5 años, observándose las relaciones más estrechas para plantaciones jóvenes entre 2 y 17 años. Además, no se encontraron diferencias significativas en la estimación de la edad con datos Landsat y SPOT, demostrando que el aumento de la resolución espacial de $30 \mathrm{~m}$ a $20 \mathrm{~m}$ no produce mejoras en las correlaciones.

Es importante destacar de los resultados de este trabajo que las ecuaciones que están en función de las bandas no corregidas tienen una aplicación específica solamente para la imagen en estudio. Imágenes correspondientes al mismo path/row y capturadas en otras fechas presentarán diferentes valores digitales (DN). Por lo tanto, las ecuaciones seleccionadas no podrán ser utilizadas directamente para estimar la edad sobre la base de imágenes de otras fechas y de otras áreas de la provincia de Corrientes. Por el contrario, las ecuaciones para estimar edades en función de las bandas corregidas se podrán aplicar a diferentes imágenes, previa corrección con el algoritmo de ATCOR2. Es decir que la utilización de la regresión sobre otras imágenes supone el logro de una satisfactoria corrección radiométrica con los factores de calibración citados en este estudio. No obstante, los valores de intensidad de la banda 4 podrían ser utilizados como indicador auxiliar durante la asignación de clases de edad de las plantaciones.

Considerando la media del error de la validación y los estadísticos de las funciones de regresión para eucalipto, es recomendable establecer dos clases de edad para el rango de edades de 4 a 12 años, siendo 6 y 10 años la marca de clases respectivamente (figura 7). Para pino se recomienda establecer dos clases de edad para el rango de edades de 4 a 26 años, siendo 9 y 20 años las marcas de clases respectivamente (figura 8). Además, para ambos géneros, y en base a interpretación visual, se podría establecer una tercera clase de edad, correspondiente a plantaciones entre 0 y 4 años, las cuales son tenuemente distinguibles en las imágenes (figuras 7 y 8). La factibilidad de separar dos clases de edad en coníferas en base a datos satelitales Landsat 5 ha sido determinada también para rodales de Picea glauca (Moench) Voss y Pinus banksiana Lamb. en Canadá (Franklin et al. 2003).

Analizando los resultados obtenidos y de los antecedentes analizados se observa que es factible estimar edades de plantaciones de Pinus spp. y Eucalyptus spp., empleando principalmente la información espectral de la banda 4 (infrarrojo cercano) de Landsat. Estos resultados sustentan el inicio en el desarrollo de métodos operacionales de estimación de edad, creando a su vez la posibilidad de utilizar esta herramienta junto con sistemas de información geográfica, no sólo con fines de optimizar inventarios forestales a través de estratificaciones, sino también para la estimación de volumen y monitoreo de crecimiento, tal como ya se desarrollaron en otros países (Trotter et al. 1997, Puhr y Donoghue 2000, Makela y Pekkarinen 2001).

En la revisión bibliográfica realizada se encuentran muy pocos trabajos que hayan analizado la aptitud de datos satelitales para la estimación de la edad de Eucalyptus spp. Por lo tanto, se sugiere profundizar tales investigaciones para dicho género. 


\section{CONCLUSIONES}

Existe una correlación significativa entre la edad de las plantaciones de Pinus spp. y Eucalyptus spp. y los valores de reflectancia e intensidad (DN). Los valores de reflectancia de la banda 4 presentan la mayor contribución en las ecuaciones de regresión establecidas, obteniéndose una correlación significativa de $-0,58$ y $-0,79$ entre los valores de reflectancia y edad para Eucalyptus spp. y Pinus spp. respectivamente.

La corrección radiométrica con ATCOR 2 presenta dificultades principalmente en las bandas visibles. Esto probablemente se deba al envejecimiento del sensor TM. La imposibilidad de lograr correcciones radiométricas adecuadas no permite la aplicación operacional de las ecuaciones establecidas para otras imágenes Landsat 5. No obstante, es factible establecer relaciones para cada imagen satelital en estudio.

Los estadísticos determinados y la posterior validación de la regresión sustentan la conformación de dos clases de edad para ambos géneros en el rango de edades analizado.

Los resultados obtenidos demuestran que se puede optimizar la extracción de información de los datos satelitales Landsat 5, utilizándolos no solamente para la delineación de las plantaciones y discriminación de géneros/especies, sino también para la estimación de variables estructurales de los rodales. Este hecho conduce a la integración de datos satelitales a un entorno de sistemas de información geográfica como una herramienta para la planificación y manejo forestal.

\section{AGRADECIMIENTOS}

Este trabajo de investigación fue financiado por el Proyecto de Desarrollo Forestal de la Secretaría de Agricultura, Ganadería, Pesca y Alimentos (SAGPyA) de la Nación Argentina. Se agradece al personal del Área Sistemas de Información Geográfica de la Dirección de Forestaciones de la SAGPyA por la provisión de información y a la CONAE por el suministro de los datos satelitales Landsat 5. Además se agradece a Héctor Gonda y José Bava del CIEFAP por su colaboración en el análisis y revisión del trabajo.

\section{REFERENCIAS}

Ahern FJ, T Erdle, DA Maclean, ID Kneppck. 1991. A quantitative relationship between forest growth rates and Thematic Mapper reflectance measurements. Int. J. of Remote Sensing 12: 387-400.

Ärdo J. 1992. Volume quantification of coniferous forest compartments using spectral radiante recorded by Landsat Thematic Mapper. International Journal of Remote Sensing 9: 1779-1786.
Bauer ME, TE Burk, AR Ek, PR Coppin, SD Lime, TA Walsh, DK Walters, W Befort, DF Heinzen. 1994. Satellite Inventory of Minnesota. Forest Resources. Photogrametric Engineering \& Remote Sensing 60(3): 287-298.

Baskerville GL. 1972. Use of logarithmic regression in the estimation of plant biomass. Can. J. Forest Res. 2: 49-53.

Bell JF, DD Marshal, GP Jonson. 1981. Tarif tables for Mountain Hemlock. Developed from an equation of total stem cubic-foot volume. Forest Research Lab. School of Forestry. Oregon State University. Research Bulletin 35. 46 p.

Bodmer HC. 1993. Untersuchung zur forstlichen Bestandeskartierung mit Hilfe von Satellitenbildern. Diss. Nr. 10080 ETH Zürich.

Chandler G, B Markham. 2003. Revised Landsat-5 radiometric calibration procedures and postcalibration dynamic ranges. IEEE Transactions on Geoscience and Remote Sensing. 41: 2674-2677.

Cohen WB, TA Spies. 1992. Estimating structural attributes of Douglas-fir Western Hemlock forest stands from Landsat and SPOT Imagery. Remote Sensing of Environment 41: 1-7.

Cohen WB, TA Spies, M Fiorella. 1995. Estimating the age and structure of forests in a multi-ownership landscape of western Oregon, USA. International Journal of Remote Sensing 16(4): 721-746.

Crist EP, RJ Kauth. 1986. The tasseled cap de-mystified. Photogrametric Engineering and Remote Sensing 52: 81-86.

Danson BA, PJ Curran. 1993. Factors affecting the remotely sensed response of coniferous forest plantations. Remote Sensing of Environment 43: 55-65.

Donoghue DNM, PJ Watt, RW Dunford, J Wilson, S Staples, S Smith, A Batts, MJ Wooding. 2002. An evaluation of the use of satellite data for monitoring Picea sitchensis plantation forest establishment and growth. ForestSAT Symposium. Heriot Watt University. Edinburgh. UK. 9 p.

Eckert S, T Kellenberger, JD Lencinas. 2005. Classification and forest parameter extraction of Patagonian Lenga forests with ASTER and Landsat ETM+ Data. PECORA 16. Global Priorities in Land Remote Sensing. October 23-27. Sioux Falls, South Dakota, USA. Proceedings PECORA 16.

Franklin SE, RJ Hall, L Smith, GR Gerylo. 2003. Discrimination of conifer height, age and crown closure classes using Landsat5 TM imagery in the Canadian Northwest Territories. Int. Journal of Remote Sensing 24(9): 1823-1834.

Furnival GM. 1961. An index for comparing equations used in constructing volume tables. Forest Science 7(4): 337-343.

Hildebrant G. 1976. Die spektralen Reflexioneigenschaften de Vegetation; Proceedings of XVI IUFRO World Congress, Oslo.

Jakubauskas ME, K Price. 2000. Regression-Based Estimation of Lodgepole Pine Forest Age from Landsat Thematic Mapper Data. Geocarto International 15(1): 19-23.

Jensen R, M Köhl. 1993. Sampling design and data analysis of the second Swiss National Forest Inventory. In Proceedings of Illvessalo Symposium on National Forest Inventories, Finland: 17-21.

Jensen JR, F Qiu, M Ji. 1999. Predictive modelling of coniferous forest age using statistical and artificialneural network approaches applied to remote sensor data. International Journal of Remote Sensing 20: 2805-2822. 
Lencinas JD. 2002. Stand Volume Estimation From Satellite Data Employing Two-Phased Sampling. 29th International Symposium on Remote Sensing of Environment. TS 35. Buenos Aires, Argentina.

Levesque J, D King. 2003. Spatial analysis of radiometric fractions from high-resolution multiespectral imagery for modelling individual tree crown and forest canopy structure and health. Remote Sensing of Environment 84: 589-602.

Makela H, A Pekkarinen. 2001. Estimation of timber volume at the sample plot level by means of image segmentation and Landsat TM imagery. Remote Sens. Environ. 77: 66-75.

Niemann KO. 1995. Remote Sensing of forest stand age using airborne spectrometer data. Photogrammetric Engineering and Remote Sensing 61: 1119-1127.

Park HM. 2003. Testing Normality in SAS, STATA and SPSS. Jeeshim and KUCC625. Hun Myoung Park Software Consultant. UITS Center for Statistical an Mathematical Computing. Consultado 30 jun 2006. Disponible en http: //pytheas.ucs.indiana.edu.

Poso S. 1988. A system for combining data from remote sensing, maps and fields measurements for forest planning purposes. University of Helsinki. Dept. of Forest Mensuration and Management, Research Notes 23, 40 p.

Puhr CB, DNM Donoghue. 2000. Remote sensing of upland conifer planning using Landsat TM Data: a case study from Galloway, south-west Scotland. International Journal of Remote Sensing 21: 633-646.

Ramsey FL, DW Shafer. 1997. The statistical sleuth. A course in methods of data analysis. Duxbury Press. Wadsworth Publishing Company. International Thomson Publishing Inc. Belmont, CA. 742 p.
Richter R. 2001. Atmospheric and Topographic Correction: Model ATCOR3, DLR-Deutsches Zentrum für Luft- und Raumfahrt, Wessling, Deutschland.

SAGPyA (Secretaría de Agricultura, Ganadería, Pesca y Alimentación). 2001. Inventario Nacional de Plantaciones Forestales. Proyecto Forestal de Desarrollo, SAGPyA. Buenos Aires. Argentina. Gincar SA. 63 p.

Schardt M. 1990. Verwendbarkeit von TM-Daten zur Klassifizierung von Baumarten und natürlichen Altersklassen. Diss. AlbertLudwigs-Universität Freiburg. 115 p.

Scheer L, A Akça, C Feldkötter. 1997. Efficient growing stock estimation from satellite data employing two-phased sampling with regression. GIS: 22-25.

Sivanpillai R, CT Smith, R Srinivasan, MG Messina, XB Wu. 2006. Estimation of managed loblolly pine stand age and density with Landsat ETM+ data. Forest Ecology and Management 223: 247-254.

Tomppo E. 1988. Standwise forest variate estimation by means of satellite images. IUFRO S4.02.05 Meeting, Aug.29 Sept. 2, 1988 Forest Station Hyytiälä, Finland, Proceedings. University of Helsinki, Department of forest mensuration and management, Research Notes 21: 103-111.

Trotter CM, JR Drymond, CJ Goulding. 1997. Estimation of timber volume in a coniferous plantation forest using Landsat TM. International Journal of Remote Sensing 18: 2209-2223.

Tuominen S, M Haakana. 2005. Landsat TM imagery and high altitude aerial photograhs in estimation of forest characteristics. Silva Fennica 39(4): 573-584.

Van Laar A, A Akça. 1997. Forest mensuration. Göttingen, Alemania. Curvillier Verlag. 418 p. 